\title{
DISSOLUTION ENHANCEMENT AND FORMULATION OF FILM COATED TABLETS OF LORNOXICAM BY PHASE TRANSITION METHOD: IN VITRO AND IN VIVO EVALUATION
}

\author{
REHAB AHMED ABDELMONEM ${ }^{1}$, RANIA MOSTAFA ABD EL GALIL ${ }^{2}$, DOAA AHMED EL-SETOUHY ${ }^{3}$, MOHAMED \\ FARID EL-MILIGI ${ }^{3}$, MOHAMED AHMED EL-NABARAWI ${ }^{3}$
}

${ }^{1}$ Department of Industrial Pharmacy, Faculty of Pharmacy, Misr University for Science and Technology, $6^{\text {th }}$ October City, Egypt, ${ }^{2 *}$ Department of Pharmaceutics, Faculty of Pharmacy, Misr University for Science and Technology, $6^{\text {th }}$ October City, Egypt, ${ }^{3}$ Department of Pharmaceutics and Industrial Pharmacy, Faculty of Pharmacy, Cairo University, Egypt

Email: dr.raniamostafa@gmail.com

Received: 17 Jan 2020, Revised and Accepted: 23 Mar 2020

\section{ABSTRACT}

Objective: This study aimed to enhance the oral solubility and dissolution of poorly soluble lornoxicam by anti-solvent precipitation, and the manufacture of oral tablets by the phase transition method.

Methods: The solvent was mixture of polyethylene glycol 400 and absolute ethanol. Three stabilizers Inutec SP1, Pluronic F127, Sucrose ester S1670 at two concentrations and two matrix formers Mannitol, and Avicel PH102 were used to obtain 12 formulae. The formulae were characterized regarding their infrared spectroscopy (IR), differential scanning calorimetry (DSC), particle size (PS) measurement, drug content and dissolution. Further characterizations were done for the optimum formula by scanning electron microscopy (SEM) and X-ray diffraction (XRD). Four tablet formulae were manufactured by phase transition method. The optimum tablets (T3) were evaluated through hardness, drug content, disintegration, dissolution, IR, and stability studies. Finally, (T3) was compared to conventional tablets in New Zealand rabbits using crossover design.

Results: The dissolution rate for the prepared formulae was enhanced, from 3.44 to 5.96 folds. Statistical significance was obtained using one and two way ANOVA among formulae. The optimum tablet formula (T3) had hardness $5.637 \pm 1.57 \mathrm{~kg}$, drug content $90.424 \pm 1.19 \%$, disintegration time $341.5 \pm 9.62 \mathrm{~s}$ and the drug dissolved $72.107 \pm 0.0025 \%$. Stability, after one month storage of the selected tablets at $\left(25^{\circ} \mathrm{c} / 60 \%\right.$ relative humidity), was satisfactory. The absorption extent of lornoxicam from (T3) compared to the conventional tablets was higher.

Conclusion: Taken together, the obtained results confirmed successfully the potential of the promising formula (T3), over the conventional tablets of lornoxicam.

Keywords: Lornoxicam, Anti-solvent precipitation, Phase transition method, In vivo study on rabbits

(C) 2020 The Authors. Published by Innovare Academic Sciences Pvt Ltd. This is an open access article under the CC BY license (http://creativecommons.org/licenses/by/4.0/] DOI: http://dx.doi.org/10.22159/ijap.2020v12i3.36867. Journal homepage: https://innovareacademics.in/journals/index.php/ijap

\section{INTRODUCTION}

Significant attention focused on nanomaterial based drug delivery has been propelled to the forefront by researchers. Owing to the fact that many emerging drug candidates have become more hydrophobic and less water soluble, designing an adequate oral dosage form as the oral route is the most common route for drug administration due to its convenience has become challenging and researchers frequently have to consider more complex drug delivery platforms [1]. The potent Lornoxicam is used for anti-inflammatory and analgesic purposes in osteoarthritis and rheumatoid arthritis [2, 3]. Lornoxicam is slightly acidic with a pKa (acid dissociation constant) of 4.7 and hence has limited dissolution in an acidic environment [4]. It is slightly lipophilic with an apparent partition coefficient of 1.8 (n-octanol/buffer $\mathrm{pH}$ 7.4) [5]. It exhibits low solubility and high permeability (class II) [6]. This can make its absorption and dissolution rate limited and thus delay the onset of action. An enhancement in the solubility and the dissolution rate can firstly, improve its oral bioavailability, secondly, improve its therapeutic efficiency and the patient compliance [7]. Anti-solvent precipitation method is an effective bottom-up technique to prepare nanosized drug particles [8]. The aim of the work is to speed up the dissolution of lornoxicam in the gastric $\mathrm{pH} 1.2$ by its formulation as nanoparticles utilizing anti-solvent precipitation technique, with the aid of different stabilizers, Inutec SP1, Pluronic F127 or Sucrose ester S1670 at different concentrations followed by lyophilization of the processed nanoparticles using either Mannitol or Avicel pH 102 as matrix formers. The lornoxicam formula which showed the optimum dissolution profile (F3) was selected for further characterization and formulation by phase transition of sugar alcohols into oral film coated tablets. Mizumoto et al., reported that oral disintegrating tablets could be manufactured using a combination of saccharides with the low and high moldability [9]. The tablet hardness was increased by the crystal change from an amorphous to a crystal state by the conditioning process. This method provides sufficient hardness and low disintegration time for tablets. Moreover, stability study was evaluated for a month, and in vivo study was also performed in rabbits to estimate the pharmacokinetic parameters for the optimized tablet formulation (T3) and to calculate the relative bioavailability in comparison to oral conventional tablets which was 2.04 folds higher.

\section{MATERIALS AND METHODS}

\section{Materials}

Lornoxicam $\left(\mathrm{C}_{13} \mathrm{H}_{10} \mathrm{Cl} \mathrm{N} \mathrm{N}_{3} \mathrm{O}_{4} \mathrm{~S}\right.$, MW: $\left.371.8192 \mathrm{~g} / \mathrm{mol}\right)$ was a gift from Global Napi drug company Ltd (6 $6^{\text {th }}$ October city, Egypt). Polyethylene glycol 400, LOBA Chemie, (India). Hydrochloric acid from Scharlau, (Spain). Absolute ethanol 99.9\% of International Company for Sup. and Med. industries Alamia, (Egypt). Phosphate buffer PH 6.8 components (Sodium Chloride, Disodium hydrogen phosphate, Potassium dihydrogen phosphate) from Adwic, El-Nasr Pharmaceutical Chemicals Co., (Egypt). Avicel pH 102 FMC Co., (Penselvania, USA). Pluronic F127 from Sigma-Aldrich, Inc., (Germany). Inutec SP1 from Beneo, (Germany). Sucrose ester S1670 from Ryoto ${ }^{\mathrm{TM}}$ (Japan). The water was distilled de-ionized water. Mannitol and Lactose anhydrous high melting point sugars from Adwic, El-Nasr Pharmaceutical Chemicals CO. (Egypt). Xylitol, low melting point sugar alcohol, Xylisorb ${ }^{\circledR}$ and Lycoat $^{\circledR}$ RS 720, medium viscosity grade from Roquette Pharma (France). Pruv ${ }^{\circledR}$ (Sodium stearyl fumarate), lubricant, from JRS Pharma (USA). Vivapharm ${ }^{\circledR}$ HPMC E5-Hypromellose from JRS Pharma (USA). Sodium nitrite from Adwic, El-Nasr Pharmaceutical Chemicals CO. (Egypt). Acetonitrile $80 \%, 0.1 \%$ Formic acid, tertiary butyl methyl ether 
(HPLC grade) were provided by Merck (Darmstadt, Germany). Lornoxicam $^{\circledR} 8 \mathrm{mg}$ (Global Pharmaceutical Industries, Egypt) was used as a reference tablet in in vivo studies.

\section{Methods}

Preparation of nanosized lornoxicam through anti-solvent precipitation method

Lornoxicam nanoparticles were produced through anti-solvent precipitation followed by freeze-drying. A mixture of absolute ethanol and the co-solvent polyethylene glycol 400 in a ratio of 2:3 respectively was used as the solvent for lornoxicam [10]. Dissolution of lornoxicam was affected by ultrasonication until completely dissolved using (ultrasonicator LC 60 H, Elma, Germany). Precooled freshly double distilled water was used as anti-solvent containing one of three stabilizers which are Pluronic F127 with concentrations $(0.02 \% \mathrm{w} / \mathrm{v}$, and $0.08 \% \mathrm{w} / \mathrm{v})$ [11], Inutec SP1 with concentrations $(0.005 \% \mathrm{w} / \mathrm{v}$, and $0.009 \% \mathrm{w} / \mathrm{v})$ [12] and Sucrose ester S1670 with concentrations $(0.001 \% \mathrm{w} / \mathrm{v}$, and $0.002 \% \mathrm{w} / \mathrm{v})$ [13]. Lornoxicam solution was completely poured into the anti-solvent (containing a certain concentration of surfactant) in a ratio 1:5 with vigorous magnetic stirring using (Magnetic stirrer, 1200 Hot plate and stirrer, Jenway, UK). Lornoxicam nanoparticles immediately precipitated from the solution upon mixing. After stirring for a predetermined time the nanoparticle suspension was sonicated using the probe sonicator (Sonics vibra cell, $20 \mathrm{KHZ} \pm 50 \mathrm{HZ}$, USA) under controlled temperature using an ice-bath with continuous sonication for $5 \mathrm{~min}$. The obtained nanoparticles were concentrated by centrifugation at 13500 rotations per minute (rpm) for $15 \mathrm{~min}$ at $4{ }^{\circ} \mathrm{C}$ using cooling centrifuge (Sigma, 3-30 K, D-37520, Germany). After the centrifugation, the supernatant was replaced with fresh double distilled water for washing. The collected nanoparticles were redispersed in deionized water containing cryoprotectants (mannitol $3 \% \mathrm{w} / \mathrm{v}$ or avicel at ratio $1: 1 \mathrm{w} / \mathrm{w}$ ), prefrozen at $-40{ }^{\circ} \mathrm{C}$ for $2 \mathrm{~h}$, and subsequently lyophilized at $-40{ }^{\circ} \mathrm{C}$ for $48 \mathrm{~h}$ to obtain lornoxicam nanoparticles powder [14].

\section{Characterization of different lornoxicam nano formulations}

DSC

DSC patterns were done for the raw drug, excipients, and the formulae using the DSC instrument (Shimadzu, Model TA - 50, ESI, Kyoto, Japan). Temperature range was $20-300{ }^{\circ} \mathrm{C}$ and the heating rate were $10^{\circ} \mathrm{C} / \mathrm{min}$. [15].

\section{IR}

The infrared spectra were done for the raw drug, excipients, and the formulae which were recorded over a wave number range of 4000 $\mathrm{cm}^{-1}$ to $400 \mathrm{~cm}^{-1}$ (IR Affinity-1, Shimadzu, Kyoto, Japan) [16].

\section{Drug content determination}

Lornoxicam content of different nanoparticle formulae was determined by dissolving $10 \mathrm{mg}$ of each formula in $100 \mathrm{ml}$ phosphate buffer pH 6.8 using sonicator, then the absorbance was measured spectrophotometrically at $376 \mathrm{~nm}$ (UV-Vis spectrophotometer, Shimadzu UV-1650 PC double beam-Japan) using phosphate buffer $\mathrm{pH} 6.8$ as the blank and the percentage drug content was calculated. Each experiment was carried out in triplicate, and the mean drug content in each formulation was determined [17].

\section{In vitro dissolution studies}

The dissolution experiment of raw lornoxicam $(8 \mathrm{mg})$ and lornoxicam nanoparticle formulae (equivalent to $8 \mathrm{mg}$ of lornoxicam) were carried out using the USP dissolution tester apparatus (II) (Dis 6000, Pharmatron, Switzerland). The stirring speed was $100(\mathrm{rpm})$, the temperature was $37.0 \pm 0.5^{\circ} \mathrm{C}$ and $900 \mathrm{ml}$ of $0.1 \mathrm{~N} \mathrm{HCl} \mathrm{pH} 1.2$ was used as the dissolution medium. Aliquots of $5 \mathrm{ml}$ were collected after 5, 10, 15, 20, 25, 30, 40, 50 and 60 min and immediately supplemented with the same volume of fresh medium. Finally, the concentrations of the collected aliquots were determined spectrophotometrically against a blank at $372 \mathrm{~nm}$ in acidic medium.
The experiment was done in triplicate and the mean values of cumulative percentage drug dissolved were plotted versus time [18].

\section{PS analysis}

The size of different lornoxicam nano formulations and poly dispersity index (PDI) were measured by dynamic laser light scattering (NanoZetasizer, Malvern ZS, Zen 3600, England). Before analysis $2 \mathrm{mg}$ of the drug nanoparticles of different formulae was dispersed in $15 \mathrm{ml}$ of deionized water and sonicated for $2 \mathrm{~min}$. The measurements were done in triplicate [19].

\section{SEM}

The external morphology of raw lornoxicam and the lornoxicam nanoparticles formula of choice were examined through scanning electron microscopy (Quanta 250, FEG, Holland). Particles of the representative samples were fixed on SEM stub using double-sided adhesive tape. Before observation, the formulae were coated with a thin layer of gold [20].

\section{XRD}

The solid state of raw lornoxicam and the lornoxicam nanoparticles formula of choice were examined using an x-ray diffractometer (Philips, X'Pert Pro, Netherlands) with secondary Monochromator. The current and voltage using Cu-radiation were generated at $35 \mathrm{~mA}$ and $45 \mathrm{kV}$, respectively. The angular range was scanned from $0{ }^{\circ}$ to $60^{\circ}$ of $2 \theta$, with a scanning speed $0.02 \%$ [21].

\section{Statistical analysis}

Statistical analysis of the results was performed using one way ANOVA followed by Post hoc analysis using Dunnett's test in terms of particle size, percentage drug content, while using two way ANOVA followed by Post hoc analysis using Dunnett's test in terms of percentage drug dissolved at $(5,20$, and $60 \mathrm{~min}$ ) of nano formulae and raw lornoxicam using SPSS software version 24 (Statistical Package for the Social Science; SPSS Inc., Chicago, IL, USA). The level of significance was set at 0.05 , and $\left({ }^{*} \mathrm{p}<0.05\right)$ was considered to be statistically significant.

\section{Preparation of film coated tablets by phase transition of sugar} alcohols

The optimum nanoparticle formula (F3) was prepared in the form of rapid release tablet using the phase transition method, a combination of two types of sugar alcohols was used, either mannitol as the high sugar alcohol $\left(166-168^{\circ} \mathrm{C}\right)$ and xylitol as low melting point sugar alcohol $\left(93-95^{\circ} \mathrm{C}\right)$ or lactose as higher melting point sugar alcohol $\left(201.6-203.3^{\circ} \mathrm{C}\right)$ and xylitol such that the ratio between the low and the high melting point sugar alcohols was 1:19. The sugar alcohols were mixed in a bottle for $3 \mathrm{~min}$, with the concentration of the low melting point sugar alcohol in the mixture being set at $5 \%$. The mixture was compressed by a single punch machine (Karishma Pharma Machines, India) under the following conditions: weight, $150 \mathrm{mg}$; compression pressure, $500 \mathrm{kgf}$; punch, 7 $\mathrm{mm}$ in diameter. The obtained tablets were coated by HPMC E- 5 for $\mathrm{T} 1$ and T3, while T2 and T4 were coated using Lycoat RS 720; the coating process was manual by spraying, then tablets were placed in a drying oven to heat at $97{ }^{\circ} \mathrm{C}$ for $30 \mathrm{~min}$. Finally, tablets were allowed to cool at room temperature [22-24].

\section{Characterization of tablets \\ Uniformity of weight}

The test was carried out according to the British Pharmacopoeia (BP) [25]. Twenty tablets from each formula, were individually weighed and the mean of tablet weights was calculated. Results are presented as mean value \pm standard deviation (SD).

\section{Tablet friability}

Twenty tablets, from each formula, were accurately weighed and placed in the drum of friabilator (Thermonik type, Campbell electronics, India). The tablets were rotated at $25(\mathrm{rpm})$ for a period of $4 \mathrm{~min}$ and then removed, dedusted and accurately re-weighed. 
The percentage loss in weight was calculated and taken as a measure of friability [25].

\section{Tablet hardness}

According to the British Pharmacopoeia, ten tablets from each formula, were tested using hardness tester (Thermonik type, Campbell electronics, India). The mean hardness was calculated in $\mathrm{kg} \pm \mathrm{SD}[25]$.

\section{Drug content uniformity}

Randomly selected ten tablets from each formula were assayed for drug content uniformity. Lornoxicam was assayed by dissolving one tablet in phosphate buffer $\mathrm{pH} 6.8$ [26] with the aid of an ultra sonicator (Elma Sonicator, Germany) for one hour to ensure complete dissolution. Lornoxicam was assayed spectrophotometerically at $\lambda_{\max } 372 \mathrm{~nm}$, using UV spectroscopy (Shimadzu-1650 PC double beam, Japan). The percentage of lornoxicam was calculated as the mean of three recordings $\pm S D$.

\section{In vitro disintegration time}

Disintegration times of the prepared tablets were determined with six tablets in $900 \mathrm{ml}$ of simulated gastric fluid Kept at $37 \pm 0.5{ }^{\circ} \mathrm{C}$ using (Thermonik type, Campbell electronics, India). According to European Pharmacopoeia (2009) specifications [27]. The disintegration time was defined as the time necessary for the tablet to completely disintegrate until no solid residue remains or only a trace amount of soft residue remains on the screen. A digital stopwatch was used to measure the disintegration time to the nearest second. All results are presented as mean value $\pm S D$.

\section{In vitro dissolution studies}

The dissolution profiles of lornoxicam in tablets compared with the raw drug were determined in a dissolution tester (Hanson Vision Elite 8, USA) following the USP Paddle Method. All tests were conducted in $900 \mathrm{ml}$ simulated gastric fluid without enzymes at $\mathrm{pH}$ 1.2. The dissolution medium was maintained at a temperature of $37 \pm 0.5^{\circ} \mathrm{C}$ with a paddle rotation speed at $100(\mathrm{rpm})$. The amount of drug used was equivalent to $8 \mathrm{mg}$. At specified time intervals $(5,10$, $15,20,25,30,40,50$, and $60 \mathrm{~min}$ ), $5 \mathrm{ml}$ aliquots were withdrawn and replaced with equal volume of fresh medium to maintain the sink condition. Samples were assayed for drug content spectrophotometerically at $372 \mathrm{~nm}$ [28]. Cumulative amount of drug dissolved in the preparations was calculated according to the calibration equation. Dissolution studies were performed in triplicates $(n=3)$.

\section{IR}

Samples of (2-3 mg) was ground with dry potassium bromide powder, and compressed into discs. The IR spectra were recorded (IR Affinity-1, Shimadzu, Kyoto, Japan) for tablet formulae, and the excipients. The test was done in triplicates [16].

\section{Statistical analysis}

The experimental results were analyzed using SPSS software version 24. One way ANOVA was used to show the significance of the difference between formulae at a level of 0.05 in terms of hardness, disintegration time and dissolution. Post hoc analysis was performed using the Scheffe test.

\section{Stability study}

A stability test was done for the optimum tablet formula (T3) prepared by direct compression using the phase transition method. The storage conditions were set at $25{ }^{\circ} \mathrm{C} / 60 \%$ relative humidity (RH) for one month in waterproof containers in desiccator containing saturated solution of sodium nitrite. Evaluation tests were done for the fresh and the stored tablets; after a week, two weeks and four weeks for their lornoxicam content, tensile strength, disintegration time and in vitro release [24].

\section{In vivo studies}

The design of this study was a comparative, randomized, single dose, two-way crossover open-label study performed in two phases using the two formulations: Lornoxicam ${ }^{\circledR} 8 \mathrm{mg}$ film coated tablets as a reference product and the optimized formula tablets (T3) (8 mg). Twelve healthy male New Zealand rabbits $(2.0-2.5 \mathrm{~kg})$ participated in the study, and were randomly assigned into two groups of equal size. The study procedure performed was approved by the Ethics Committee of Faculty of Pharmacy, Cairo University (PI 1947), Egypt. The animals were kept in individual cages under well-defined and standardized conditions (humidity, and temperature controlled room), fed with standard food and water access, and allowed to fast overnight for $12 \mathrm{~h}$ [29]. On the study day, each rabbit in the first group received equivalent amount to $(8 \mathrm{mg})$ of conventional tablet (Treatment A). The tablets were placed gently into the mouth of the rabbits and swallowed with the aid of the water. Rabbits of the second group received equal doses of lornoxicam through oral administration of optimum formula (T3) (Treatment B). From the start of the study time, the rabbits remained at the study site under controlled dietary and liquid intake until the end of the study day. The washout time was one week. Venous blood samples (250 $\mu$ ) were collected in heparinized glass tubes to prevent blood clotting at the following scheduled time intervals: 0 (predose), 15, 30, 45, 60, $90 \mathrm{~min}, 2,3,4,6,8,12,15$, and $24 \mathrm{~h}$ after administration of both treatments. Plasma was immediately separated from the blood cells via centrifugation (3000 rpm) for $10 \mathrm{~min}$ (Centurion Scientific Ltd., Chichester, UK), kept in glass tubes and then deep frozen at $-25^{\circ} \mathrm{C}$ till assayed.

\section{Instrumentation}

The analysis was performed using a Shimadzu Prominence (Shimadzu, Japan) series LC system equipped with degasser (DGU20A3) and solvent delivery unit (LC-20AD) with an auto-sampler (SIL-20A). The system was used to inject $25 \mu \mathrm{l}$ aliquots of the processed samples on a C18, 100A $(50 \times 4.6 \mathrm{~mm})$ (Phenomenex, USA), $5 \mu \mathrm{m}$ particle size. A sensitive and validated LC-MS/MS was adopted for the separation and quantitation of lornoxicam using Torsemide as an internal standard (IS) [30]. The mobile phase consisted of acetonitrile and $0.1 \%$ formic acid in water $(80: 20 \mathrm{v} / \mathrm{v}$ ) was pumped at $1 \mathrm{ml} / \mathrm{min}$. MS/MS detection in positive ion mode using AB Sciex (Foster City, CA, USA) API-3200 mass spectrometer was used for quantitation. The analytical data were processed by Analyst Software version 1.6 (Applied Biosystems Inc., Foster city, CA) [31].

\section{Standard solution and sample preparation}

To prepare the standard calibration samples, aliquots of $1 \mathrm{ml}$ rabbit plasma were spiked with lornoxicam stock solution $(50 \mathrm{ng} / \mathrm{ml})$ and an aliquot of $100 \mu \mathrm{l}$ of Torsemide solution the internal standard (IS) to produce calibration standards at the following concentrations: 1 , $3,12.5,100,300,625,1000 \mathrm{ng} / \mathrm{ml}$. For sample preparation, $1 \mathrm{ml}$ of rabbit plasma and $100 \mu \mathrm{l}$ of Torsemide solution (IS) was vortexed in $10 \mathrm{ml}$ glass tubes for $1 \mathrm{~min}$. Five milliliters of tertiary butyl methyl ether were added vortexed for another 1 min then centrifuged at $3000(\mathrm{rpm})$ for $10 \mathrm{~min}$. The organic layer $(3 \mathrm{ml})$ was transferred to clean glass tube and evaporated to dryness using centrifugal vacuum concentrator at $45^{\circ} \mathrm{C}$. The dry residue was reconstituted in $200 \mu \mathrm{l}$ mobile phase and an aliquot of $20 \mu \mathrm{l}$ of this solution was loaded into LC-MS/MS.

\section{Pharmacokinetic parameters and statistical calculations}

Peak concentrations $\left(\mathrm{C}_{\max }\right)$ and peak times $\left(\mathrm{T}_{\max }\right)$ were derived directly from the experimental points. The other pharmacokinetic parameters; $\left(\mathrm{AUC}_{0-24}, \mathrm{AUC}_{0-\infty}, \mathrm{Kel}_{\mathrm{el}}\right.$ and $\mathrm{t}_{1 / 2 \mathrm{e}}$ ) were computed by non-compartmental analysis using Kinetica Software (version 4.4.1). The pharmacokinetic parameters of the two tested formulations (test and reference) were compared by using non-parameteric for independent samples (MannWhitney's test) using the SPSS software version 24. The significance of the difference was determined at $\left({ }^{*} \mathrm{p}<0.05\right)$.

\section{RESULTS}

Preparation of nanosized lornoxicam through anti-solvent precipitation method

Lornoxicam nanoparticles were prepared by the anti-solvent precipitation method. The drug solution was introduced to generate 
high supersaturation, results in a high nucleation rate and produces a large number of nuclei, which reduced the solute mass for subsequent growth. The growth of nucleating crystals could be arrested by using a stabilizer through a steric or electrostatic mechanism [32]. For hydrophobic drugs like lornoxicam, water is most commonly used as anti-solvent. In terms of the solvent, blend of absolute ethanol and polyethylene glycol 400 in a ratio 2:3 screened by trial and error was used. The solubilization power was correlated with the co-solvent polarity; the greater the difference in polarity between the two solvents the greater the power of solubilization [10]. The stabilizer needs to have a good affinity for the drug particles, possesses a fast diffusion rate and effective adsorption onto the drug particle surface. So, the choice of appropriate solvent-stabilizer pair is empirical. The physical state of the formed particles was significantly influenced by many parameters as stirring rate; higher stirring rate favored the formation of smaller and more uniform drug particles, also the drug concentration and the solvent volume ratio [33]. The preparation temperature; a lower temperature can inhibit the particle growth, therefore the particles with small size were formed as a result of the high nucleation rate and low growth rate at low temperature [34]. After several trials and errors, the parameters of the method were, three stabilizers Inutec SP1, Pluronic F127, Sucrose ester S1670, each in two different ratios above and below their critical micelle concentrations of $0.009 \% \mathrm{w} / \mathrm{v}, 0.1 \% \mathrm{w} / \mathrm{v}$, and $0.0014 \% \mathrm{w} / \mathrm{v}$ respectively [11-13], the temperature of anti-solvent below $3{ }^{\circ} \mathrm{C}$, the stirring rate was $1500(\mathrm{rpm})$, the ratio between the solvent and antisolvent was 1:5, the composition of the different formulae has complied in table 1 .

Table 1: Composition of different lornoxicam nano formulae

\begin{tabular}{|c|c|c|c|c|c|}
\hline Formula & $\begin{array}{l}\text { Inutec SP1 } \\
(\% \mathrm{w} / \mathrm{v})\end{array}$ & $\begin{array}{l}\text { Pluronic F127 } \\
(\% \mathrm{w} / \mathrm{v})\end{array}$ & $\begin{array}{l}\text { Sucrose ester S1670 } \\
(\% \mathrm{w} / \mathrm{v})\end{array}$ & $\begin{array}{l}\text { Mannitol } \\
(\% \mathrm{w} / \mathrm{v})\end{array}$ & $\begin{array}{l}\text { Avicel pH } 102 \\
\text { (mg) }\end{array}$ \\
\hline $\mathrm{F}_{1}$ & 0.009 & & & 3 & \\
\hline$F_{2}$ & 0.009 & & & & 30 \\
\hline $\mathrm{F}_{3}$ & 0.005 & & & 3 & \\
\hline $\mathrm{F}_{4}$ & 0.005 & & & & 30 \\
\hline$F_{5}$ & & 0.02 & & 3 & \\
\hline $\mathrm{F}_{6}$ & & 0.02 & & & 30 \\
\hline $\mathrm{F}_{7}$ & & 0.08 & & 3 & \\
\hline $\mathrm{F}_{8}$ & & 0.08 & & & 30 \\
\hline $\mathrm{F}_{9}$ & & & 0.002 & 3 & \\
\hline $\mathrm{F}_{10}$ & & & 0.002 & & 30 \\
\hline $\mathrm{F}_{11}$ & & & 0.001 & 3 & \\
\hline$F_{12}$ & & & 0.001 & & 30 \\
\hline
\end{tabular}

*All the formulae contain $30 \mathrm{mg}$ lornoxicam

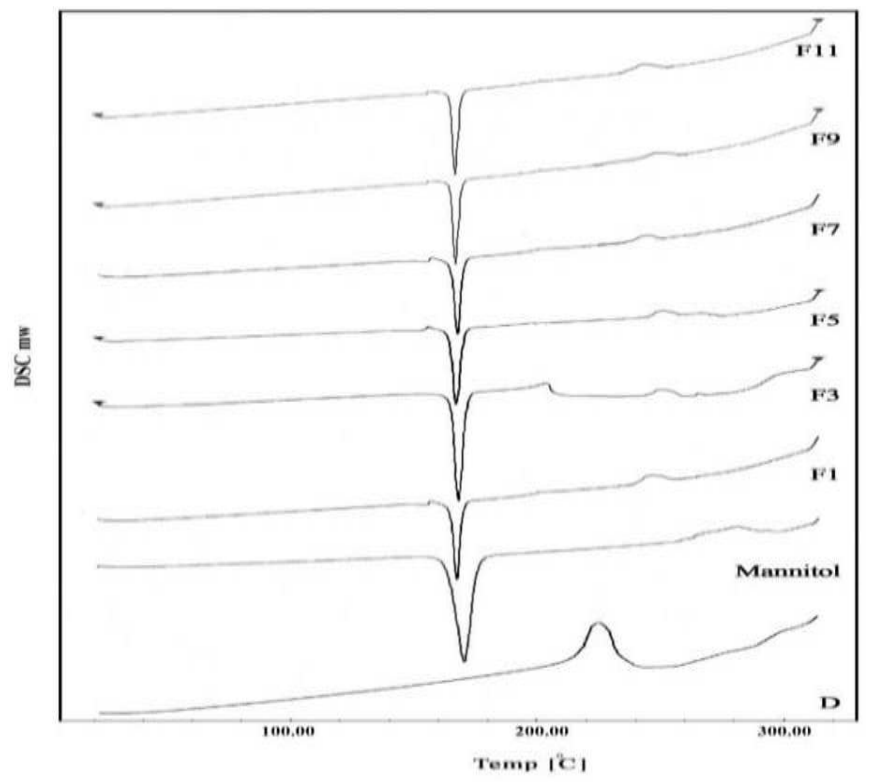

Fig. 1 (a): DSC thermograms of Lornoxicam (D), Mannitol, F1, F3, F5, F7, F9 and F11

\section{Characterization of nanoparticles}

\section{DSC}

The compatibility of lornoxicam with the excipients was investigated using DSC since it is considered as a rapid method for evaluating the possible incompatibilities between drugs and excipients [35]. The DSC thermograms of raw lornoxicam, different formulae and the excipients are shown in fig. 1. Lornoxicam DSC thermogram exhibited a sharp exothermic peak at $233.8^{\circ} \mathrm{C}$ corresponding to drug melting [36]. Avicel pH 102 showed a slightly exothermic effect above $300^{\circ} \mathrm{C}$ that might be attributed to its melting or decomposition. Mannitol showed a sharp endothermic peak at $167^{\circ} \mathrm{C}$. It was evident that the exothermic peaks corresponding to both mannitol and avicel were preserved in the thermograms of all formulae. The lornoxicam exothermic peak was also evident in all of the thermograms of its formulae which might indicate compatibility. However, noticeable broadening in lornoxicam peak intensity was observed in some thermograms. This is probably attributed to the differences in geometry of the mixture samples reported by other authors [37]. Therefore, further compatibility investigation was performed applying infrared spectroscopy study. 


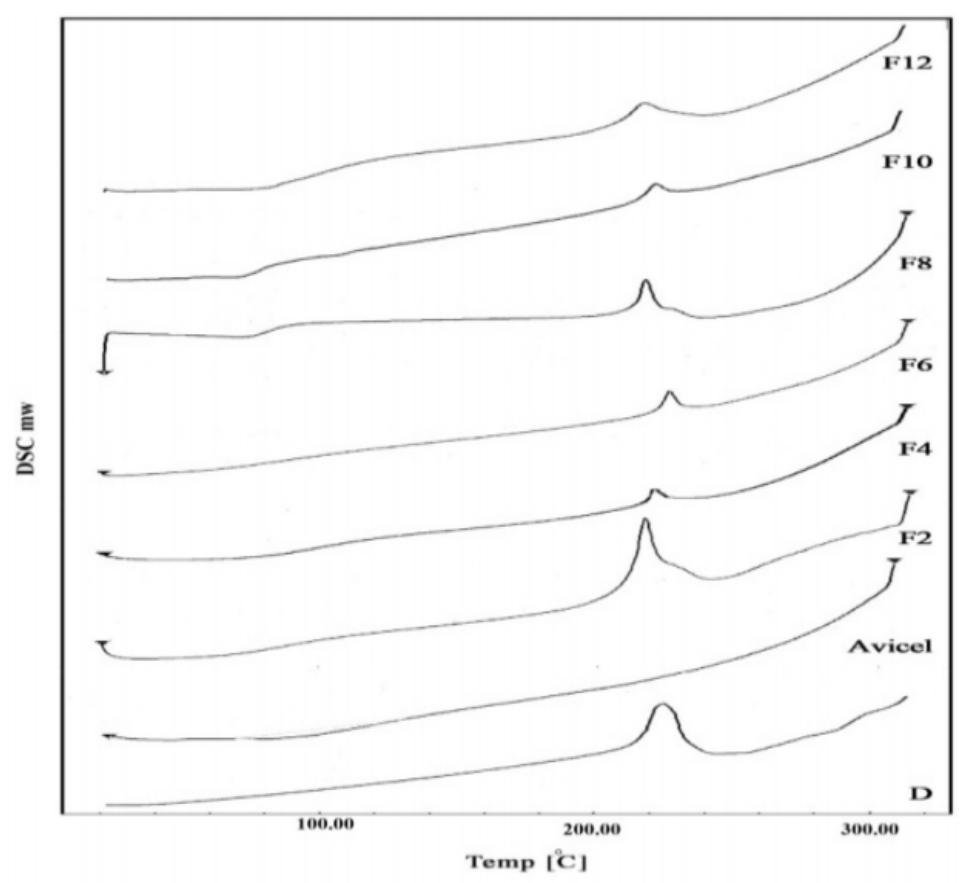

Fig. 1(b): DSC thermograms of Lornoxicam (D), Avicel, F2, F4, F6, F8, F10 and F12

IR

The Fourier-transform infrared spectra (FTIR) of lornoxicam and the formulae were recorded and presented in fig. 2. It is clearly apparent that the IR spectrum of lornoxicam showed a characteristic peak at $3090 \mathrm{~cm}^{-1}$ corresponding to-NH stretching vibration. An intense absorption peak was found at $1642 \mathrm{~cm}^{-1}$ due to the stretching vibration of the $\mathrm{C}$ O $\mathrm{O}$ group in the primary amide. Other peaks were observed at $1597 \mathrm{~cm}^{-1}$ and at $1559 \mathrm{~cm}^{-1}$ showed the bending vibrations of the $\mathrm{N}-\mathrm{H}$ group in secondary amide. Peaks obtained at $1157 \mathrm{~cm}^{-1}, 1387 \mathrm{~cm}^{-1}, 1336 \mathrm{~cm}^{-1}$ were due to stretching vibrations of $\mathrm{O}$ SOO $\mathrm{O}$ group. Other prominent peaks appeared at $827.94 \mathrm{~cm}^{-1}$ corresponding to- $\mathrm{CH}$ aromatic ring bending and at $766.8 \mathrm{~cm}^{-1}$ due to $\mathrm{C}-\mathrm{Cl}$ bending vibration. It was clearly evident that the IR spectra of the different formulae showed no significant difference in peak intensities and wavelengths indicating the absence of chemical interaction between the drug and the excipients confirming the DSC results presented formerly. Therefore, the latter was considered in conjunction with DSC to reach a definite conclusion of drug excipient compatibility [38].

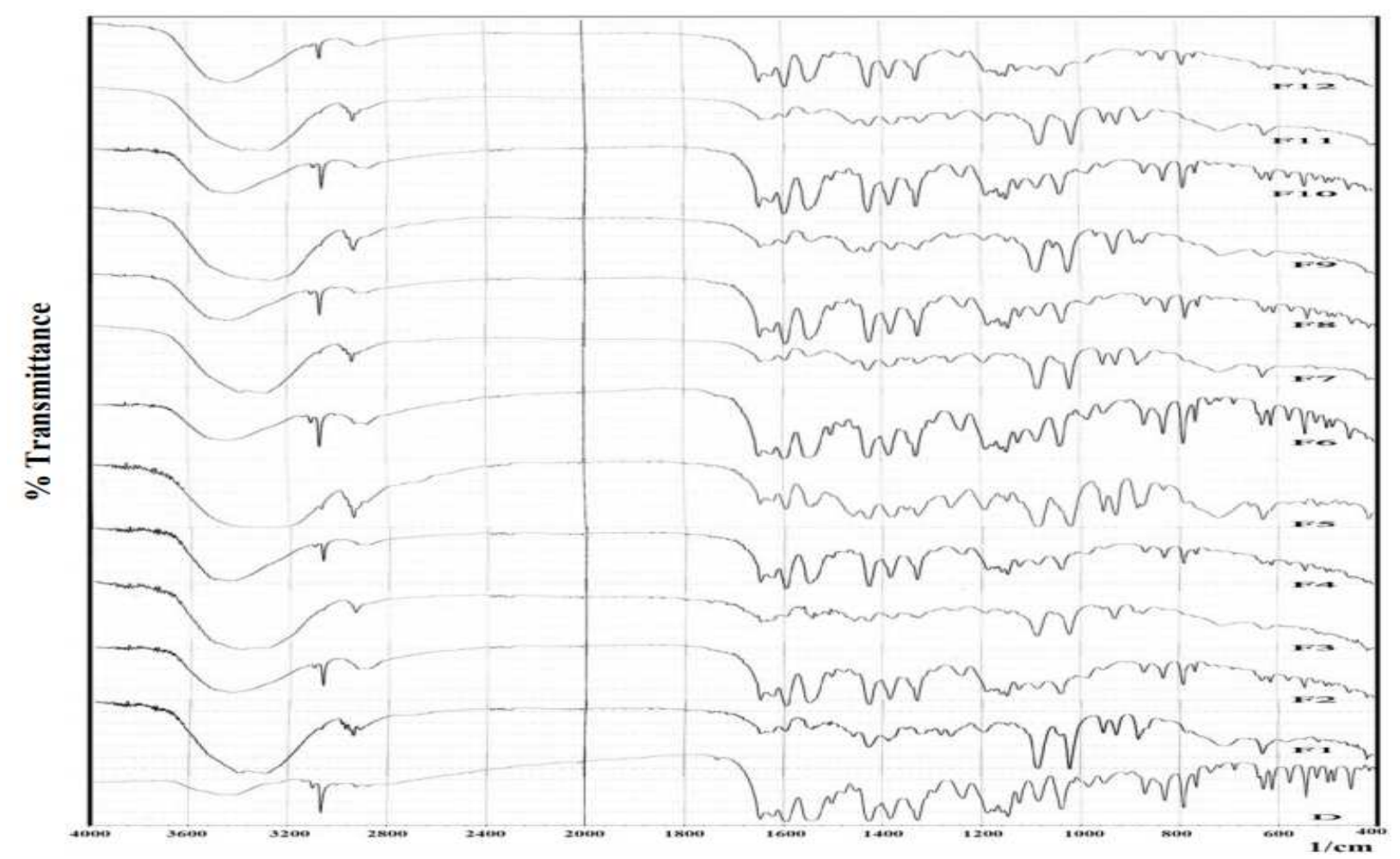

Fig. 2: FTIR spectra of Lornoxicam (D) and nanoparticles formulations 


\section{Drug content determination}

Table 2 showed the average percentage drug content of different formulae, which ranged from $25.759 \pm 0.119 \%$ to $100.508 \pm 0.034 \%$ and the standard deviation from triplicate determinations. It is evident that some formulae had high drug content and some were low; this is probably attributed to the number of nuclei formed at the solvent/anti-solvent interface and the influence of concentration on the viscosity [39]. The process parameters including the effect of temperature during mixing, rate of mixing, drug concentration, solvent/anti-solvent ratio, the choice of stabilizers used and their concentrations, cryoprotectants used, all played roles in degree of supersaturation and the nucleation rates which offer the potential to produce a large number of submicrometer particles in the final suspension, if the growth can be arrested by stabilizers [32]. The statistical analysis showed a significant difference between formulae by one way ANOVA followed by Dunnett's test, and the highest content was in F3.

Table 2: Percentage drug content of different formulae

\begin{tabular}{ll}
\hline Formula & Drug content (\%) \\
\hline F1 & $88.436 \pm 0.001$ \\
F2 & $58.366 \pm 0.063$ \\
F3 & $100.508 \pm 0.034$ \\
F4 & $25.759 \pm 0.119$ \\
F5 & $96.606 \pm 0.165$ \\
F6 & $59.453 \pm 0.307$ \\
F7 & $67.195 \pm 0.123$ \\
F8 & $83.210 \pm 0.123$ \\
F9 & $87.05 \pm 0.035$ \\
F10 & $50.647 \pm 0.240$ \\
F11 & $75.047 \pm 0.038$ \\
F12 & $44.926 \pm 0.039$ \\
\hline
\end{tabular}

${ }^{*}$ All values are $($ mean \pm SD (standard deviation $), n=3$ )

\section{In vitro dissolution studies}

In vitro dissolution studies for raw lornoxicam and the processed nanoparticles were done using the $8 \mathrm{mg}$ dose [40] for one hour in $0.1 \mathrm{~N} \mathrm{HCl}$ at $\mathrm{pH} 1.2$. The cumulative percentage of the drug dissolved as a function of time from the prepared lyophilized formulae is illustrated in fig. 3. The general features of lornoxicam dissolution profiles revealed a high initial flash dissolve within the first $15 \mathrm{~min}$ from F1 (69.108\%) and F3 (65.794\%). The highest amount of drug dissolved after one hour was from F3 (74.484\%), F5 (75.375\%), F6 $(75.735 \%)$, which show insignificant differences between them $\left({ }^{*} \mathrm{P}>0.05\right)$, while $\mathrm{F} 11$ showed the lowest amount of drug dissolved $(43.762 \%)$. It was clearly observed that the percentage of drug dissolved from raw lornoxicam was very slow (12.7\%) after one hour. However, it was apparent that lornoxicam dissolution significantly $\left({ }^{*} \mathrm{p}<0.05\right)$ improved when the anti-solvent precipitation method used and nanoparticles produced, from 3.4 to 5.96 folds.
According to Noyes-Whitney equation, the drug release rate is linearly proportional to the surface area exposed to the medium [41]. The accelerated dissolving rate of lornoxicam nanoparticles could be mainly ascribed to their greater surface area in comparison with the raw drug. The results showed that the use of stabilizers (Inutec SP1, or Pluronic F127, or Sucrose ester S1670) in concentrations near or lower than their critical micelle concentrations, was effective in inhibiting crystal growth due to the presence of the hydrodynamic boundary layer surrounding the nanocrystals as well as adsorption of the polymer molecules on the growing crystal faces [42]. The mechanism of polymer adsorption on the crystal surface can be explained on the basis of hydrogen bonding between drug molecules and polymer. Two way ANOVA followed by Dunnett's test in terms of percentage lornoxicam dissolved at given time intervals $(5,20,60 \mathrm{~min})$ from nanoparticles formulae and raw lornoxicam using Tukey HSD and Dunnett two sided showed significant difference $\left({ }^{*} \mathrm{P}<0.05\right)$.

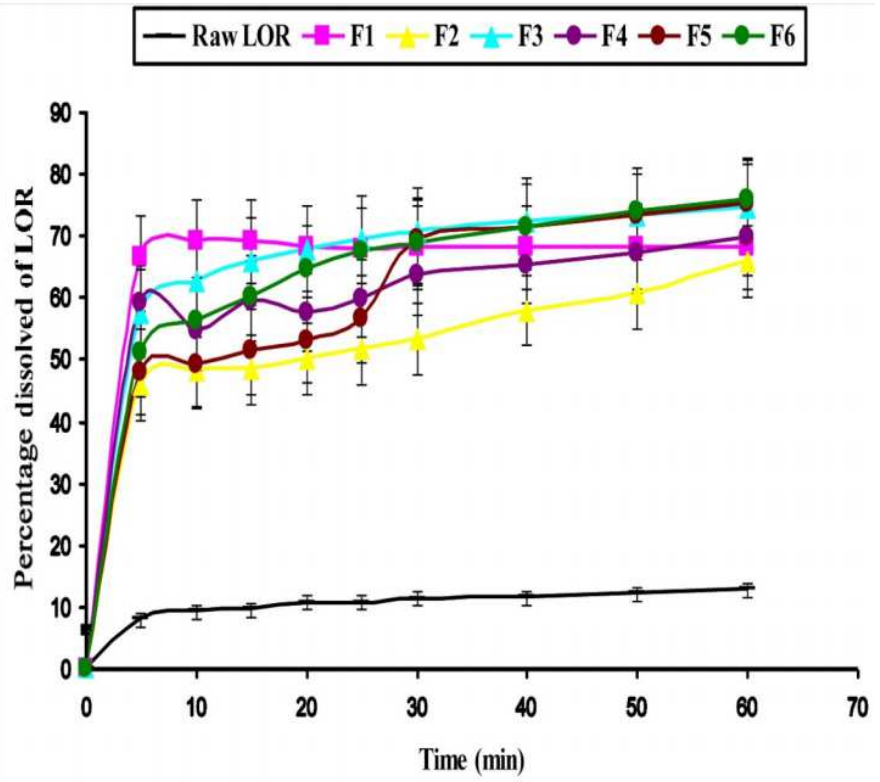

Fig. 3(a): Percentage lornoxicam dissolved from F1 to F6 in $0.1 \mathrm{~N} \mathrm{HCl}$, compared with raw lornoxicam, (mean $\pm \mathrm{SD}, \mathrm{n}=3)$ 


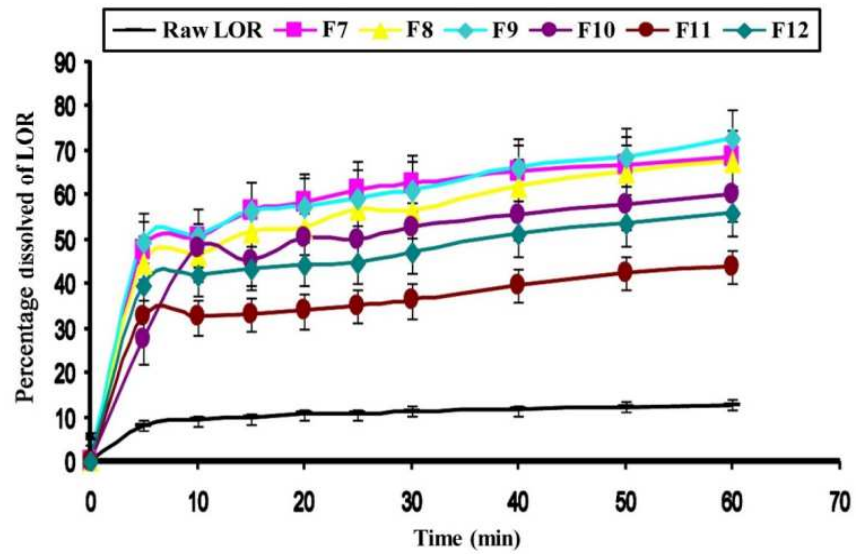

Fig. 3(b): Percentage lornoxicam dissolved from F7 to F12 in $0.1 \mathrm{~N} \mathrm{HCl}$, compared with raw lornoxicam, (mean $\pm S D, n=3)$

\section{PS analysis}

The particle size distribution of lornoxicam nanoparticles using zetasizer was determined. The mean particle size and polydispersity index of the prepared nanoparticles were calculated from the autocorrelation function of the intensity of the light scattered from the particles. It could be seen that the mean particle size of the nanoparticles obtained via the anti-solvent precipitation method ranged from $333.45 \mathrm{~nm}$ to $741.825 \mathrm{~nm}$ which were shown in table 3.

Particle size formation includes several steps, namely particle nucleation, molecular growth and agglomeration or aggregation, and their rate determines the final particle size and its distribution. The driving force for this process is the supersaturation, which determines not only the nucleation rate, but also the diffusion-controlled growth rate [43]. The lornoxicam nanoparticles were significantly smaller and more uniform than the raw lornoxicam, which indicates better solubility [44]. The increase in mean particle size and the polydispersity index (PDI $>0.5$ ) in some formulae could have been caused by the aggregation of particles during the freeze-drying. It can thus be concluded that the stabilizers used are effective in arresting the particle growth, but may not be very effective to prevent aggregation. Statistical analysis showed significant difference between formulae by one way ANOVA followed by Dunnett's test, and the smallest size was F3. Therefore, the latter was considered in conjunction with dissolution study to reach a definite conclusion of enhancement of dissolution due to reduction of particle size.

Table 3: Particle size measurements for different formulae

\begin{tabular}{lll}
\hline Formula & Size (nm) & PDI \\
\hline F1 & $365.825 \pm 1.375$ & $0.778 \pm 0.053$ \\
F 2 & $566.525 \pm 10.124$ & $0.558 \pm 0.028$ \\
F 3 & $338.725 \pm 13.025$ & $0.78 \pm 0.018$ \\
F 4 & $461.925 \pm 14.875$ & $0.607 \pm 0.045$ \\
F 5 & $333.45 \pm 14.45$ & $0.718 \pm 0.025$ \\
F 6 & $647.475 \pm 18.825$ & $0.425 \pm 0.035$ \\
F 7 & $349.825 \pm 22.425$ & $0.825 \pm 0.071$ \\
F 8 & $502.725 \pm 20.275$ & $0.506 \pm 0.021$ \\
F 9 & $362.925 \pm 6.075$ & $0.889 \pm 0.000$ \\
F 10 & $687.062 \pm 14.388$ & $0.347 \pm 0.031$ \\
F 11 & $655.000 \pm 24$ & $0.813 \pm 0.033$ \\
F 12 & $741.825 \pm 15.275$ & $0.412 \pm 0.033$ \\
\hline
\end{tabular}

*All values are (mean $\pm S D, n=3)$, PDI (Polydispersity index)

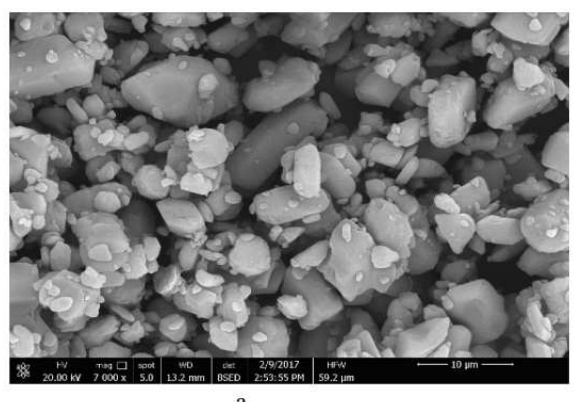

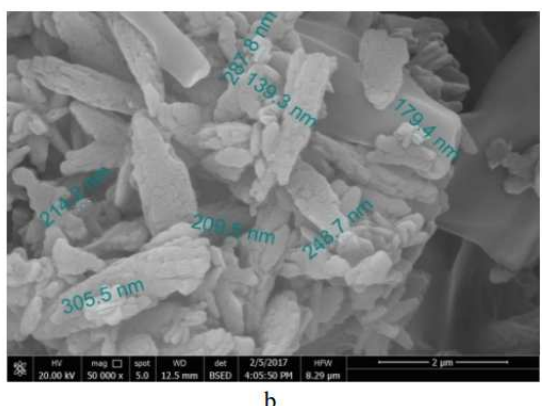

Fig. 4: Representative SEM for (a) Raw drug, (b) F3

\section{SEM}

Morphology of raw lornoxicam and the selected nanoparticles formula (F3) were shown in fig. 4. It can be observed that raw drug particles exhibited irregular shape and a broad size distribution. F3 with the stabilizers used showed spherical or twisted cuboid shape in whole. Under high magnification, it could be clearly evident that these agglomerates or particle assemblies were composed of a large 
number of individual nanoparticles with a size of approximately 300 nm.

\section{XRD}

X-ray diffraction analysis was performed to investigate the effect of the anti-solvent precipitation method on the crystallinity of lornoxicam in the nanoparticles formulae, where the selected nanoparticle formulation and the raw lornoxicam powder were compared in fig. 5. The diffraction pattern of lornoxicam revealed several sharp, high-intensity peaks observed at $(2 \theta)$ angles of $8.78^{\circ}$, $13.47^{\circ}, 14.31^{\circ}, 15.10^{\circ}, 18.91^{\circ}, 20.51^{\circ}, 21.53^{\circ}, 22.97^{\circ}, 24.70^{\circ}$, $25.40^{\circ}, 28.08^{\circ}, 30.49^{\circ}$ and $45.84^{\circ}$, indicating the crystalline nature of the drug, while the diffractograms of the selected nanoparticle formulae showed a disappearance of some diffraction peaks and reduction in intensity of the remaining peaks, indicating that the processed particles were in amorphous form. The amorphous state of the lornoxicam nanoparticles would also help accelerate the drug dissolving rate as well [41]. These promising results encourage for further studies on optimum formula into tablet form and in vivo study for enhancement of oral bioavailability of lornoxicam.

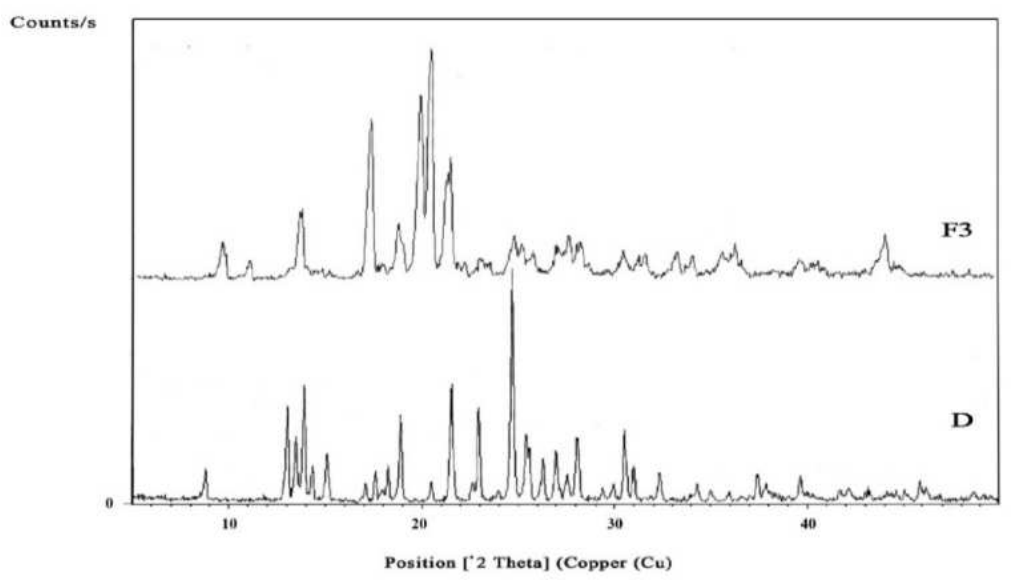

Fig. 5: XRD patterns of Lornoxicam (D) and F3

\section{Preparation of film coated tablets by phase transition of sugar alcohols}

The optimum formula (F3) was prepared using the phase transition method by direct compression. The phase transition method was chosen as it is new, simple method of preparing rapid disintegrating tablets without any special apparatus, focused on the compactability of saccharides using a combination of low and high compactability saccharides [45]. Although, this novel preparation method reported by Mizumoto et al., focused on the melting point of saccharides and sugar alcohols in order to produce rapid disintegrating tablets of sufficient hardness and low disintegration time, we use these benefits for preparation of oral tablets in an acidic medium and the results were satisfied. The objectives of this study are to produce oral film coated tablets, which has a sufficient hardness for handling, as before processing the tablets were fragile, low disintegration time and can be manufactured by commonly used production methods and equipment. The composition of tablet formulae manufactured by the phase transition method was shown in table 4 .

Table 4: Composition of tablet formulae (T1, T2, T3, and T4)

\begin{tabular}{lllll}
\hline Components & T1 & T2 & T3 & T4 \\
\hline Powder & 59.455 & 49.085 & 60.897 & 1.17 \\
Lubricant (Pruv) & 1.17 & 1.17 & 4.396 & 1.17 \\
Xylitol & 4.468 & 4.987 & - & 4.753 \\
Mannitol & 84.907 & 94.758 & 83.537 & - \\
Lactose & - & - & $2 \%$ & - \\
HPMC (E-5) & $2 \%$ & - & - & $2 \%$ \\
LycoatRS720 & - & $2 \%$ & 150 & 150 \\
Total weight & 150 & 150 & & 150 \\
\hline
\end{tabular}

*All the tablet formulae components are in (mg)

\section{Characterization of tablets}

All formulations resulted in successfully elegant tablets that withstood manual handling. As shown in table 5, the tablets were located within the acceptable weight variation range. According to compendial standards, the tablets comply with the friability test as the weight loss during the friability test was less than $1 \%$, indicating that the tablets were non-fragile and could be handled easily. The mean hardness value ranged from 3.88 to $6.79 \mathrm{Kg}$. It was apparent that the tablet hardness was affected by the heating process and low meting point sugar alcohol content. All the tablets containing about $5 \%$ xylitol showed hardness above 2 kilo pond (kp). It is generally recognized that sufficient hardness would be $2 \mathrm{kp}$ or higher [46, 47]. Xylitol in tablets would melt at $93{ }^{\circ} \mathrm{C}$, since the melting point of xylitol is $93-95^{\circ} \mathrm{C}$ [48]. Accordingly, the melting of xylitol caused by heating probably influences the hardness of tablets. It is well known that the tablet hardness decreases with increasing the pore size in case of common compressed tablets [49, 50]. However, the tablet hardness increased with the pore size after heating, this probably due to diffusion of melted xylitol in tablets and then solidified again when left at room temperature after heating so the hardness increased due to greater bonding surface area between the powder particles [51, 52]. It was evident that tablet formulae (T3, T4) containing lactose became harder after heating, compared with that of tablet formulae (T1, T2) containing mannitol, this is probably due to fine particle size of lactose powder than that of mannitol, which produces a greater bonding surface area with xylitol when melted. Added to that, (T4) was the hardest formula due to the greater content of lactose than that in (T3). There was significant difference between formulae $\left({ }^{*} \mathrm{P}<0.05\right)$ by one way ANOVA using post hoc 
followed by Scheffe test, which showed homogeneity between (T3, $\mathrm{T} 4)$. In vitro disintegration studies showed that (T1, T2) were of longer disintegration times compared with (T3, T4), added to that (T1, T3) were of lower disintegration time compared with (T2, T4). These probably attributed to the composition of (T3, T4); which contain amorphous form saccharide (lactose anhydrous) [53] by virtue of its fine particles and high solubility, the tablet formulae acquired hardness and brittleness and these were apparent in superior hardness of $(\mathrm{T} 3, \mathrm{~T} 4)$ over $(\mathrm{T} 1, \mathrm{~T} 2)$ and at the same time their faster disintegration. The disintegration time of $\mathrm{T} 3$ and conventional tablets were also compared and the results were $341.5 \pm 9.62 \mathrm{~s}$, and $490 \pm 10 \mathrm{~s}$ respectively. In $\mathrm{T} 2$ and $\mathrm{T} 4$ the film coating was Lycoat RS720 [54]; (hydroxyl propyl Pea starch) of medium viscosity and formed more cohesive films, that are less likely to break up or dissolve easily than HPMC E-5 (hydroxyl propyl methylcellulose) which is of low viscosity. There was statistical significance $\left({ }^{*} \mathrm{P}<0.05\right)$ between formulae regarding the disintegration time by one way ANOVA using post hoc followed by Scheffe test.

Table 5: Characterization of tablets

\begin{tabular}{llllll}
\hline Formula & $\begin{array}{l}\text { Weight variation } \\
\text { (mg) }\end{array}$ & $\begin{array}{l}\text { Hardness } \\
\text { (kg) }\end{array}$ & $\begin{array}{l}\text { Drug content } \\
\text { (\%) }\end{array}$ & $\begin{array}{l}\text { Friability } \\
\text { (\%) }\end{array}$ & $\begin{array}{l}\text { Disintegration time } \\
\text { (s) }\end{array}$ \\
\hline T1 & $146.43 \pm 1.36$ & $3.88 \pm 1.03$ & $88.79 \pm 5.34$ & 0 & 3 \\
Drug Content uniformity \\
T2 & $146.53 \pm 0.52$ & $3.54 \pm 0.94$ & $87.74 \pm 2.57$ & $0.68 \pm 0.67$ & $415 \pm 25.11$ \\
T3 & $146.93 \pm 1.35$ & $5.62 \pm 1.42$ & $90.42 \pm 1.19$ & $0.10 \pm 0.03$ & $341.5 \pm 9.62$ \\
T4 & $148.33 \pm 1.51$ & $6.80 \pm 1.25$ & $85.54 \pm 2.91$ & $0.23 \pm 0.09$ & $364.3 \pm 10.63$ \\
\hline
\end{tabular}

*All values are (mean $\pm S D, n=3)$

\section{In vitro dissolution studies}

In film coated tablets the dissolving percentage in $\mathrm{T} 1$ and $\mathrm{T} 3$ were superior over the rest of the formulae which were $76.346 \pm 0.005$ and $72.107 \pm 0.002$ respectively. It was also evident in fig. 6 that the preparing method or the excipients used have no retarding effect on the release of lornoxicam from tablets compared with the dissolution profile of optimum nanoparticle formula; such that the dissolving percentage from F3 was $74.484 \pm 0.005$. It was also confirmed that the phase transition method provided the tablets with sufficient hardness while keeping its quick disintegration and dissolution rate. These results correlate well with disintegration time testing results, where HPMC E-5 film coating resulted in shorter disintegrating time than that of lycoat. These results were confirmed statistically by one way ANOVA using post hoc followed by Scheffe test, showed an insignificant difference $(* \mathrm{P}>0.05)$ and homogeneity between F3, (T1, T2, T3, T4) and between (T1, T2, T3, T4).

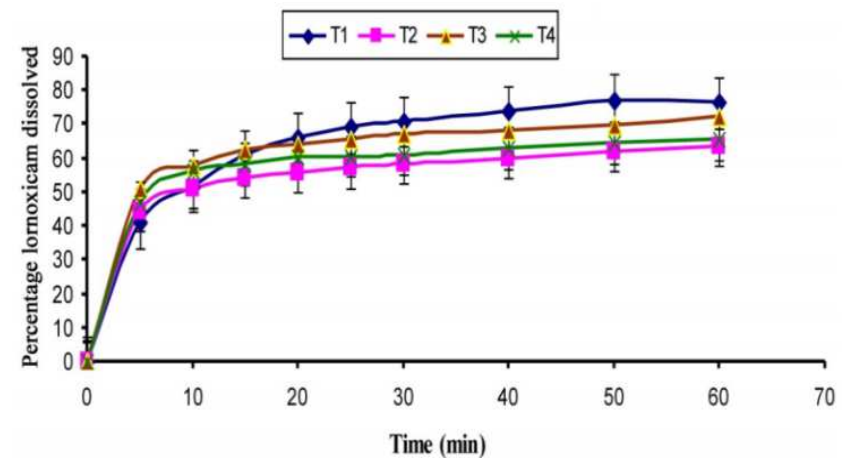

Fig. 6: In vitro dissolution profiles of tablet formulae in gastric simulated fluid at $\mathrm{pH} 1.2$ and $37^{\circ} \mathrm{C},(\mathrm{mean} \pm \mathrm{SD}, \mathrm{n}=3)$

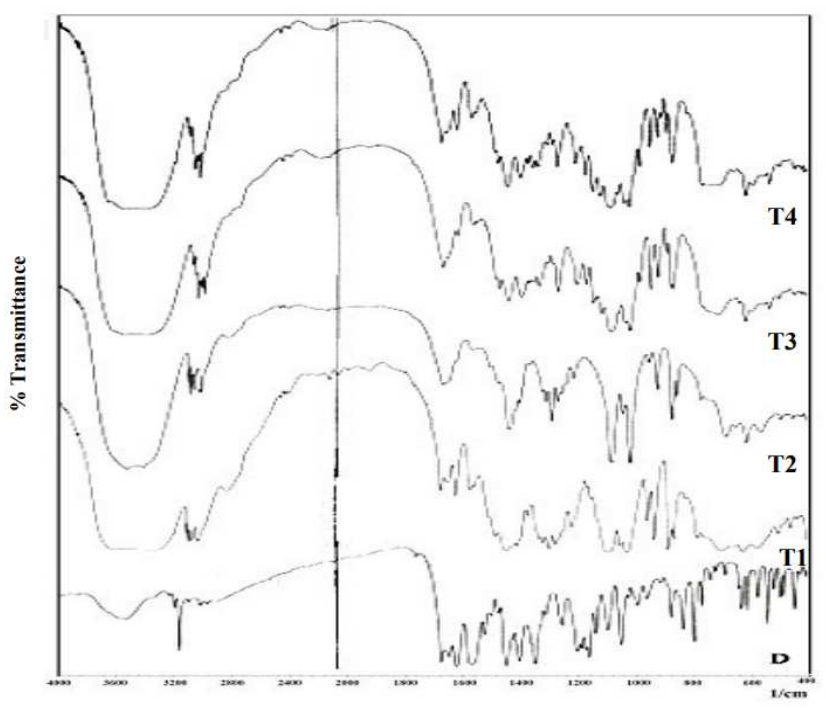

Fig. 7: FTIR spectra of tablet formulae compared with raw lornoxicam 
IR

The IR spectra of different tablet formulations and pure excipients used were recorded and presented in fig. 7. It was clearly apparent from tablet formulations that the characteristic peaks of lornoxicam were at their same positions with the different excipients used in tablet formulations. Moreover, these spectra can be simply regarded as the superimposition of lornoxicam spectrum and the investigated excipients spectra. This could indicate the absence of chemical interaction between drug and excipients in different tablet formulations.

\section{Stability studies}

The visual and physical inspection of the selected tablets (T3) conditioned at $25{ }^{\circ} \mathrm{C} / 60 \% \mathrm{RH}$ for one month [24] revealed no remarkable changes in the physical characteristic (texture, color, and porosity). Also, no remarkable change in the thickness, diameter and drug content of the selected tablets (T3). The hardness and disintegration time of tablets slightly increased with storage time. These data suggested that the xylitol content (5\%) in the formula; used as low melting point sugar alcohol which was responsible during the heating process in phase transition method for inter-particle bonds between high melting point sugar alcohol (lactose) particles, required a long time to return to a crystalline solid. Analyzing the dissolution data of the stored and fresh tablets indicated that storing the tablets at the specified conditions $\left(25{ }^{\circ} \mathrm{C} / 60 \% \mathrm{RH}\right)$ had no marked effect on drug dissolution as shown in fig. 8. In addition, sugar alcohols are very sensitive to humidity, so that it is important for formulation development to select the moisture-proof packaging to prevent changing of tablet properties under the humidity condition. The observed stability of lornoxicam in T3 tablets can be attributed to the lyophilization process which can enhance the product stability in the dry state $[55,56]$.

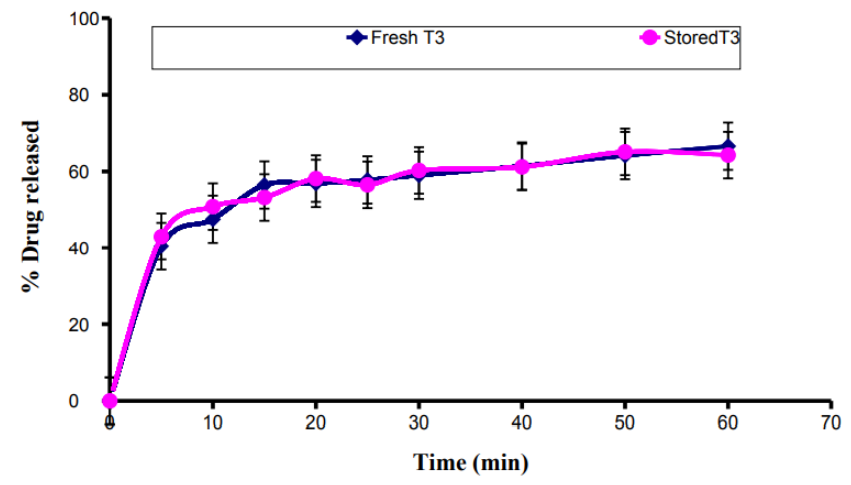

Fig. 8: Comparison between dissolution profiles of $\mathrm{T} 3$ in fresh and after $4 \mathrm{w}$ of storage condition, mean of readings $(\mathrm{n}=3) \pm \mathrm{SD}$

\section{In vivo study and pharmacokinetic analysis}

The calibration curve of lornoxicam showed a linear response across the concentration range used from 1 to $1000 \mathrm{ng} / \mathrm{ml}$. The assay method showed a linear relationship between lornoxicam concentration and its peak area ratio to the internal standard and the determination coefficient $\left(\mathrm{R}^{2}\right)$ was found to be 0.997 . As the assay method can be used for the quantitative determination of the drug in plasma [57]. The mean plasma concentration-time curves following the administration of Lornoxicam ${ }^{\circledR} 8 \mathrm{mg}$ tablets and T3 tablets were shown in fig. 9 and the mean pharmacokinetic parameters were reported in table 6 . Results showed that the $\mathrm{C}_{\max }$ of T3 was $1408.92 \pm 62.194 \mathrm{ng} / \mathrm{ml}$ compared with $707.203 \pm 62.011$ $\mathrm{ng} / \mathrm{ml}$ for Lornoxicam ${ }^{\circledR}$ (conventional tablets). The $\mathrm{C}_{\max }$ increased by 1.99 folds indicating that T3 tablets, improved oral absorption of lornoxicam. The $\mathrm{T}_{\max }$ was the same in both $\mathrm{T} 3$ and conventional tablets which were consistent with reported values (1-2 h) [58]. It was observed that the $\mathrm{AUC}_{0-24}$ in $\mathrm{T} 3$ was higher than that of conventional tablets by more than 2 folds, similarly the AUC $0-\infty$ was higher by 1.99 folds. These results showed that the amount of drug absorbed through the optimum formula T3 was remarkably higher than that from conventional tablets. The relative bioavailability was improved by $203.794 \%$. Finally, the elimination half-life was slightly shorter in T3 than conventional tablets and this indicated the effectiveness and the rapid action of T3 and it was consistent with the pharmacokinetics theory, in which an increase in absorption should not affect elimination. The statistical analysis comparing the pharmacokinetics parameters between the two treatments was the non-parametric test Mann-Whitney for independent samples showed that the mean rank of $\mathrm{T} 3$ in $\left(\mathrm{C}_{\max }, \mathrm{AUC}_{0-24}, \mathrm{AUC}_{0-\infty}\right.$, and $\left.\mathrm{K}_{\mathrm{el}}\right)$ were higher than that in conventional tablets and showed significant difference $\left({ }^{*} \mathrm{P}<0.05\right)$ regarding $\left(\mathrm{C}_{\max }, \mathrm{AUC}_{0-24}\right.$, and $\left.\mathrm{AUC}_{0-\infty}\right)$, while no significance regarding $\left(\mathrm{T}_{\max }, \mathrm{K}_{\mathrm{el}}\right.$, and $\left.\mathrm{t}_{1 / 2 \mathrm{e}}\right)$ and these results were confirmed by Wilcoxon $\mathrm{W}$ and Z-calculated tests.

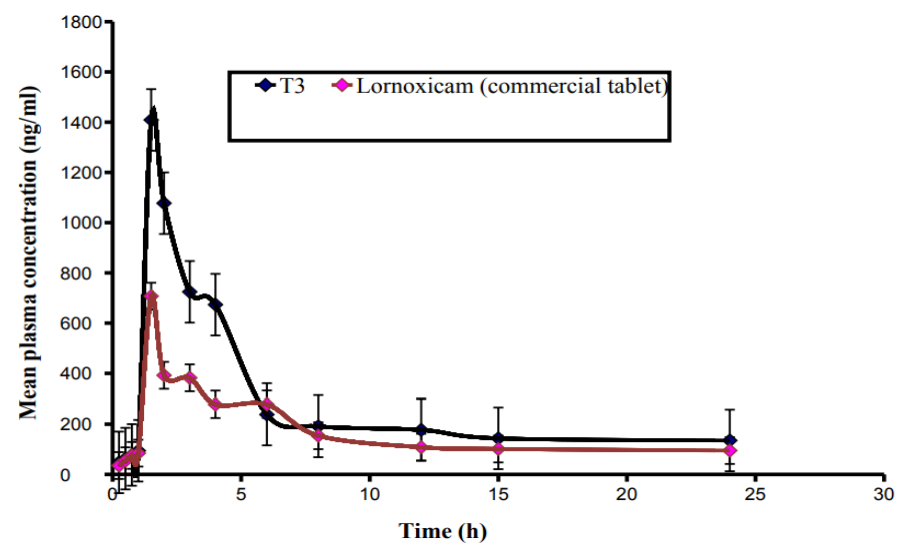

Fig. 9: Mean plasma lornoxicam concentrations $\pm S D,(n=3)$, following administration of $T 3$ and Lornoxicam ${ }^{\circledR}$ tablets in rabbits 
Table 6: The mean pharmacokinetic parameters $\pm S D,(n=3)$, of lornoxicam after administration of $T 3$ and Lornoxicam ${ }^{\circledR}$ tablets to rabbits

\begin{tabular}{|c|c|c|c|c|c|c|c|}
\hline Parameters & $\begin{array}{l}C P_{\max } \\
(\mathrm{ng} / \mathrm{ml})\end{array}$ & $\begin{array}{l}T_{\max } \\
\text { (h) }\end{array}$ & $\begin{array}{l}\text { AUC }_{(0-24)} \\
(\mathrm{ng} . \mathrm{h} / \mathrm{ml})\end{array}$ & $\begin{array}{l}\text { AUC }_{(0-\infty)} \\
\text { (ng. h/ml) }\end{array}$ & $\begin{array}{l}K_{\text {el }} \\
\left(h^{-1}\right)\end{array}$ & $\begin{array}{l}t_{1 / 2 e} \\
\text { (h) }\end{array}$ & ${ }^{*} \mathrm{RB} \%$ (relative bioavailability) \\
\hline T3 & $\begin{array}{l}1408.92 \\
\pm 62.19\end{array}$ & $\begin{array}{l}1.5 \\
\pm 0\end{array}$ & $\begin{array}{l}16574.22 \\
\pm 577.97\end{array}$ & $\begin{array}{r}29640.267 \\
\pm 2570.368\end{array}$ & $\begin{array}{l}0.054 \\
\pm 0.015\end{array}$ & $\begin{array}{l}13.58 \\
\pm 2.690\end{array}$ & $203.794 \%$ \\
\hline Lornoxicam $^{\circledR}$ tablets & $\begin{array}{l}707.20 \\
\pm 62.01\end{array}$ & $\begin{array}{l}1.5 \\
\pm 0\end{array}$ & $\begin{array}{l}8132.82 \\
\pm 232.46\end{array}$ & $\begin{array}{l}14924 \\
\pm 2485.450\end{array}$ & $\begin{array}{l}0.045 \\
\pm 0.012\end{array}$ & $\begin{array}{l}16.715 \\
\pm 5.164\end{array}$ & ----- \\
\hline
\end{tabular}

\section{CONCLUSION}

The dissolution of lornoxicam was successfully enhanced by producing nanoparticles through anti-solvent precipitation using three different stabilizers Inutec SP1, Pluronic F127, Sucrose ester S1670. F3 which was formulated using Inutec SP1 displayed superior dissolution profile, drug content and small particle size. It was taken as the optimum formula and successfully manufactured into rapid release film coated tablets through the novel method (phase transition of sugar alcohols) by direct compression. T3 was the optimum tablet formula, which showed a superior dissolution profile, drug content, hardness, and disintegration time. Stability study on T3 showed, that the storage conditions did not affect the lornoxicam content, or the in vitro release, but slightly increase the hardness and the disintegration time. Overall, the in vivo pharmacokinetic study showed significantly higher $\mathrm{C}_{\max }, \mathrm{AUC}_{0-24}$, and relative bioavailability demonstrate the potential of the formulation and its rapid absorption to provide effective and efficient tablets of lornoxicam by the oral route.

\section{ACKNOWLEDGMENT}

The authors are thankful to Misr University for Science and Technology, College of Pharmacy and Cairo University Faculty of Pharmacy for providing all the necessary equipment and support.

\section{FUNDING}

Nil

\section{AUTHORS CONTRIBUTIONS}

All the authors have contributed equally.

\section{CONFLICT OF INTERESTS}

The authors declare that they have no conflict of interest.

\section{REFERENCES}

1. Sunita SS, Avinash HH. Preparation and evaluation of nanosuspensions for enhancing the dissolution of lornoxicam by antisolvent precipitation technique. Indo Am J Pharm Res 2014;4:398-405.

2. EL-Menshawe SF, Eissa E, Ali AA, Abderhman AA. Enhancement of lornoxicam solubility by inclusion complexation with cyclodextrin: preparation and characterization. Int J Pharm Pharm Sci 2017;9:132-8.

3. Nalini R, Ezhilramya J. A comparative study of efficacy and safety of lornoxicam and diclofenac as postoperative analgesics after mastoidectomy surgery. Int J Pharm Pharm Sci 2017;9:7783.

4. Hitzenberger G, Radhofer Welte S, Takacs F, Rosenow D. Pharmacokinetics of lornoxicam in man. Postgrad Med J 1990;66 Suppl 4:S22-6.

5. Radhofer Welt S, Dittrich P. Determination of the novel nonsteroidal anti-inflammatory drug lornoxicam and its main metabolite in plasma and synovial fluid. J Chromatogr B Biomed Appl 1998;707:151-9.

6. Kumar S, Bhargava D, Thakkar A, Arora S. Drug carrier systems for solubility enhancement of BCS class II drugs: a critical review. Crit Rev Ther Drug Carrier Syst 2013;30:217-56.

7. Shakeel F, Haq N, Alanazi F, Alsarra I. Solubility of antiinflammatory drug lornoxicam in ten different green solvents at different temperatures. J Mol Liq 2015;209:280-3.

8. Salem HF, Kharshoum RM. Nanoprecipitation technique for preparation of sterically stabilized risperidone nano- suspension: in vitro and in vivo study. Int J Pharm Pharm Sci 2016;8:136-42

9. Agiba AM, Eldin AB. Insights into formulation technologies and novel strategies for the design of orally disintegrating dosage forms: a comprehensive industrial review. Int J Pharm Pharm Sci 2019;11:8-20.

10. Lee JH, Chun IK. Effects of various vehicles and fatty acids on the skin permeation of lornoxicam. J Pharm Invest 2012;42:235-41.

11. Lin Y, Alexandridis P. Temperature-dependent adsorption of Pluronic F127 block copolymers on to carbon black particles dispersed in aqueous media. J Phys Chem B 2002;106:10834-44.

12. Srinarong $P$, Hämäläinen $S$, Visser $M R$, Hinrichs $W L$, Ketolainen J, Frijlink HW. Surface-active derivative of inulin (Inutec ${ }^{\circledR S P 1}$ ): Is a superior carrier for solid dispersions with a high drug load. J Pharma Sci 2011;100:2333-42.

13. Soultani S, Ognier S, Engasser JM, Ghoul M. Comparitive study of some surface active properties of fructose esters and commercial sucrose esters. Colloids Surfaces: A Physicochemical Engineering Aspects 2003;227:35-44.

14. Lonare AA, Patel SR. Antisolvent crystallization of poorly water soluble drugs. Int J Chem Eng Appl 2013;4:337-41.

15. Dumas JP, Gibout $S$, Zalewski L. Interpretation of calorimetry experiments to characterize phase change materials. Int J Therm Sci 2014;78:48-55.

16. Hasson KJ, Ghareeb MM. Evaluation of innovative co-processed additive for direct compression tablets using atorvastatin and diazepam as model drugs. Int J Pharm Pharm Sci 2016;8:201-7.

17. Gattani S, Moon R. Formulation and in vitro evaluation of tablet containing gliclazide nanocrystals for solubility and dissolution enhancement using soluplus. Int J Pharm Sci Res 2018;9:133-9.

18. Raghad AN, Hind EZ. Enhancement of candesartan cilexetil dissolution rate by using different methods. A J Pharm Clin Res 2015;8:320-6.

19. Yeap SP, Lim J, Ngang HP, Ooi BS, Ahmad AL. Role of particleparticle interaction towards effective interpretation of ZAverage and particle size distributions from dynamic light scattering (DLS) analysis. J Nanosci Nanotechnol 2018;18: 6957-64.

20. Brännstrom K, Islam T, Gharibyan AL, Lakovleva I, Nilsson L, Lee CC, et al. The properties of amyloid- $\beta$ fibrils are determined by the nucleation pathway. J Mole Biol 2018;430:1940-9.

21. Shewale S, Shete AS, Doijad RC, Kadam SS, Patil VA, Yadav AV. Formulation and solid state characterization of nicotinamidebased co-crystals of fenofibrate. Ind J Pharm Sci 2015;77:32834 .

22. Kuno Y, Kojima M, Ando S, Nakagami H. Evaluation of rapidly disintegrating tablets manufactured by phase transition of sugar alcohols. J Controlled Release 2005;105:16-22.

23. Kuno Y, Kojima M, Nakagami H, Yonemochi E, Terada K. Effect of the type of lubricant on the characteristics of orally disintegrating tablets manufactured using the phase transition of sugar alcohol. Eur J Pharm Biopharm 2008;69:986-92.

24. Kuno Y, Kojima M, Ando S, Nakagami H. Effect of preparation method on properties of orally disintegrating tablets made by phase transition. Int J Pharm 2008;355:87-92.

25. British Pharmacopoeia. The stationary office under licence from the controller of Her Majesty's stationary office for the department of health. London; 2007. p. A111, A112, A153.

26. Jassim ZE, Mohammed MF, Sadeq ZA. Formulation and evaluation of fast dissolving film of lornoxicam. Asian J Pharm Clin Res 2018;11:174-85. 
27. Pharmacopoeia E. 6th ed. published by Council of Europe. Strasbourg, France; 2009. p. 1169-70.

28. Pharmacopoeia B. The stationary office under licence from the controller of Her Majesty's stationary office. Norwich; 1998. p. 174.

29. Abraham S, Deveswaran R, Anbu J, Furtado S, Baharath S. Pharmacokinetic studies of a chronotherapeutic drug delivery system of lornoxicam by LC-MS/MS method. Int J Appl Pharm 2018;10:88-93.

30. Moutasim MY, ElMeshad AN, El-Nabarawi MA. A pharmaceutical study on lornoxicam fast disintegrating tablets: formulation and in vitro and in vivo evaluation. Drug Delivery Transl Res 2017;7:450-9.

31. Elsharawy AM, Shukr MH, Elshafeey AH. Optimization and in vivo evaluation of duloxetine hydrochloride buccoadhesive lyophilized tablets. J Drug Delivery Sci Tech 2019;52:282-91.

32. Matteucci ME, Hotez MA, Johnston KP, Williams III RO. Drug nanoparticles by antisolvent precipitation: Mixing energy versus surfactant stabilization. Langmuir 2006;22:8951-9.

33. Bilati U, Allémann E, Doelker E. Development of nanoprecipitation method intended for the entrapment of hydrophilic drugs into nanoparticles. Eur J Pharm Sci 2005;24:67-75.

34. Cushing BL, Kolesnichenko VL, O'Connor CJ. Recent advances in the liquid-phase synthesis of inorganic nanoparticles. Chem Rev 2004;104:3893-946.

35. Tomassetti M, Catalnabi A, Rossi V, Vecchio S. Thermal analysis study of the interactions between acetaminophen and excipients in solid dosage forms and in some binary mixtures. J Pharm Biomed Anal 2005;37:949-55.

36. Merck Index. $13^{\text {th }}$ ed. Merck and Co. Inc., Whitehouse Station, NJ, USA; 2001. p. 1000.

37. Botha SA, Lotter AP. Compatibility study between naproxen and tablet excipients using differential scanning calorimetry. Drug Dev Ind Pharm 1990;16:673-83.

38. Joshi BV, Patil VB, Pokharkar VB. Compatibility studies between carbamazepine and tablet excipients using thermal and nonthermal methods. Drug Dev Ind Pharm 2002;28:687-94.

39. Galindo Rodriguez S, Allémann SE, Fessi H, Doelker E. Physicochemical parameters associated with nanoparticle formation in the salting out, emulsification-diffusion and nanoprecipitation methods. Pharm Res 2004;21:1428-39.

40. Hillstorm C, Jakobsson JG. Lornoxicam: pharmacology and usefulness to treat acute postoperative and musculoskeletal pain a narrative review. Expert Opin Pharmacother 2013;14:1679-94

41. Dong Y, Ng WK, Hu J, Shen S, Tan RB. A continous and highly effective static mixing process for antisolvent precipitation of nanoparticles of poorly water-soluble drugs. Int J Pharm 2010;386:256-61

42. Zimmermann A, Millqvist Fureby A, Elema MR, Hansen T, Müllertz A, Hovgaard L. Adsorption of pharmaceutical excipients onto microcrystals of siramesine hydrochloride: effects on physico-chemical properties. Eur J Pharm Biopharm 2009;71:109-16.
43. Xia D, Quan P, Piao H, Piao H, Sun S, Yin Y, et al. Preparation of stable nitrendipine nanosuspensions using the precipitationultrasonication method for enhancement of dissolution and oral bioavailability. Eur J Pharm Sci 2010;40:325-34.

44. Kocbek P, Baumgartner S, Kristl J. Preparation and evaluation of nanosuspensions for enhancing the dissolution of poorly soluble drugs. Int J Pharm 2006;312:179-86.

45. Masih A, Kumar A, Singh S, Tiwari AK. Fast dissolving tablets: a review. Int J Curr Pharm Res 2017;9:8-18.

46. Rudnic EM, Schwartz JD. Oral solid dosage forms. In: Alfonso RG. editor. Remington: The Science and Practice of Pharmacy. 20th ed. Philadelphia: Lippincot Williams and Wilkins Inc; 2000. p. 858-93.

47. Bhavani D, Rao NG. Formulation and evaluation of valsartan fast disintegrating tablets by vacuum drying technique. Asian J Pharm Clin Res 2016;9:73-9.

48. Dobrowolski A, Pieloth D, Wiggers H, Thommes M. Electrostatic precipitation of submicron particles in a molten carrier. Pharmaceutics 2019;11:1-7.

49. Juppo AM. Relationship between breaking force and pore structure of lactose, glucose and mannitol tablets. Int J Pharm 1996;127:95-102.

50. Mattsson S, Nystrom C. The use of mercury porosimetry in assessing the effect of different binders on the pore structure and bonding properties of tablets. Eur J Pharm Biopharm 2001;52:237-47.

51. Nystrom C, Karehill PG. Studies on direct compression of tablets: XVI. The use of surface area measurements for the evaluation of bonding surface area in compressed powders. Powder Technol 1986;47:201-9.

52. Nystrom C, Alderborn G, Duberg M, Karehill PG. Bonding surface area and bonding mechanism-two important factors for the understanding of powder compactability. Drug Dev Ind Pharm 1993;19:2143-96.

53. Agrawal A, Duhedia M, Deng W, Shepard K, Zong L, Povilaitis E, et al. Development of tablet formulation of amorphous solid dispersions prepared by hot melt extrusion using quality by design approach. AAPS PharmSciTech 2016;17:214-32.

54. Kathpalia H, Patil A. Formulation and evaluation of orally disintegrating films of levocetrizine dihydrochloride. Indian J Pharm Sci 2017;79:204-11.

55. Kianfar F, Antonijevic M, Chowdhry B, Boateng JS. Lyophilized wafers comprising carrageenan and pluronic acid for buccal drug delivery using model soluble and insoluble drugs. Colloids Surf B 2013;103:99-106.

56. Szymanska E, Winnicka K. Stability of chitosan-a challenge for pharmaceutical and biomedical applications. Mar Drugs 2015;13:1819-46.

57. Wong A, Xiang X, Ong P, Mitchell EQY, Syn N, Wee I, et al. A review on liquid chromatography-Tandem Mass spectrometry methods for rapid quantification of oncology drugs. Pharmaceutics 2018;10:1-20.

58. El-Mahmoudy A. Pharmacokinetics of lornoxicam in rabbits after single intravenous bolus and intramuscular administrations. Int J Pharmacol Toxicol 2016;4:66-73. 